\title{
Generalized graphic-analytical model for evaluation of the fatality I structural collapse production mechanism on a building affected by an explosion
}

\author{
Gabriel Vasilescu ${ }^{1 *}$, Attila Kovacs ${ }^{1}$, Ciprian Jitea ${ }^{1}$, Doru Anghelache ${ }^{2}$, and Florian Stoian ${ }^{2}$ \\ ${ }^{1}$ National Institute for Research and Development in Mine Safety and Protection to Explosion - \\ INSEMEX Petrosani, Department of Safety of Explosion and Pyrotechnic Articles, G-ral V. Milea \\ Street 32-34, Petrosani, Romania \\ ${ }^{2}$ University of Petrosani, Doctoral School, Universitatii Street 22, Petrosani, Romania
}

\begin{abstract}
The paper highlights the generalized grapho-analytical model of analysis and evaluation of the mechanism of occurrence of the event scenario for the production of fatality/structural collapse in the case of a building affected by explosion. This mathematical model is based on research results in the field of civil explosives for the technological/occupational risks estimation and assessment, as well as threats to the security of protected areas that may be vulnerable through acts of malice. The process of quantitative risk assessment associated with explosion phenomena as a result of the detonation of an explosive charge, allows estimating result indicators based on the use of algorithms and models specific to associated hazards, in order to model the effects and consequences of event scenarios.
\end{abstract}

\section{Introduction}

In general, there are three types of quantitative risk assessment (QRA) models: (a) physicsbased, (b) empirical, and (c) semi-empirical. Physics-based models can be developed to model explosives safety scenarios, however they are, by necessity, quite complex and therefore expensive to develop. Physics-based models may also assume behaviour that does not exist in the real world. Empirical models, which report only data points available from tests and accidents, are by their nature limited in scope. Semi-empirical models, which use anchor points from available data but "fill in the gaps" with physics-based algorithms, often offer the best compromise between development cost, capabilities, and acceptance of results. The methodology presented in this paper are semi-empirical. The amount of conservatism is inversely related to the amount of available data. If there are very few (or no) data points available to anchor an algorithm, the model is designed to err on the side of caution. However, when an algorithm has been corroborated by test and/or accident data, the model does not include the same level of conservatism. This is important because the inclusion of

\footnotetext{
* Corresponding author: dragos.vasilescu@,insemex.ro
} 
conservatism would prevent model results from comparing well with the empirical data anchor points (i.e., reality).

In 1999, the United States (US) Department of Defence (DoD) recognized the need for and usefulness of a risk-based approach for explosives safety siting. The DoD Risk-Based Explosives Safety Criteria Team (RBESCT) was chartered to develop the methodology required and then create a model. This led to the creation of the Safety Analysis for Explosives Risk (SAFER) software tool, which is a semi-empirical QRA model for the US DoD $[1,2,3]$.

\section{Material and method}

Throughout the QRA process, hazards to persons are estimated based upon various algorithms and models specific to each hazard type. Most models are based upon research or testing that characterizes effects and consequences for "typical" scenarios with exposures at moderate distances, often defined by QD. Standard safety criteria require most or all personnel to be a minimum distance away from a potential hazard. In some scenarios, one or more persons are located uncharacteristically close to a hazard. In the event of an explosive accident, the consequences to an individual at a close-in range are not well defined or studied.

Models used to estimate hazards to persons at "typical" ranges could be extrapolated to estimate the hazards close-in, but this approach results in applying far-field effects to the near-field. Simpler models are often employed in QRA models for this region close to the event, in part to ensure conservatism. The Simplified Close-In Fatality Mechanism approach uses a conservative technique to override the standard consequence model for close-in scenarios. The general concept of the Simplified Close-In Fatality Mechanism model is presented in Figure 1[4].

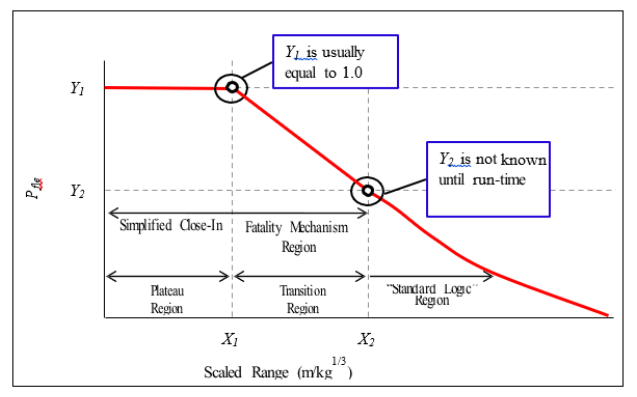

Fig. 1. The Simplified Close-In Fatality Mechanism - General concept by region.

For extremely close-in regions, the $\mathrm{P}_{f \mid e}$ value is assigned a plateau value equal to some maximum setting. This Plateau Region of the Simplified Close-In Fatality Mechanism model extends to a predefined scaled range, $\mathrm{X}_{1}$. A second scaled range, $\mathrm{X}_{2}$, is defined as the distance at which there is confidence in the results of the scientific algorithms. Beyond this distance is referred to as the Standard Logic Region. The range between the Plateau Region and the Standard Logic Region is defined as the Transition Region. The specific implementation of this model is described for Building Collapse, as the follow as in Figure 1.The division of the three regions of this model are delineated by the two points $\left(\mathrm{X}_{1}, \mathrm{Y}_{1}\right)$ and $\left(\mathrm{X}_{2}, \mathrm{Y}_{2}\right)$. The Building Collapse algorithm involves setting three things: Step 1: $\mathrm{X}_{1}, \mathrm{Y}_{1}$ for each ES building type; Step 2: $\mathrm{X}_{2}, \mathrm{Y}_{2}$ for each ES building type; Step 3: The form of the transition between $\left(\mathrm{X}_{1}, \mathrm{Y}_{1}\right)$ and $\left(\mathrm{X}_{2}, \mathrm{Y}_{2}\right)$. 


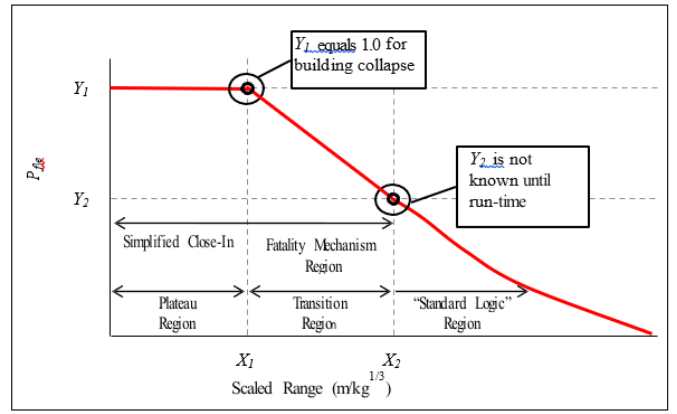

Fig. 2. Building Collapse Model.

\section{a) Determining the $X_{1}, Y_{1}$ for each ES building type}

For the Building Collapse fatality mechanism, $\mathrm{Y}_{1}$ is set to a value of 1.0. The starting point for setting $\mathrm{X}_{1}$ was to use the consequence software DIRE to estimate the probability of fatality due to building collapse. Analysis of Death and Injuries Resulting from Explosions (DIRE) is specialized software for providing personnel protection through explosive consequence assessment. The problem was set up as an open PES Structure with the ES Structure varying $[5,6,7]$. The amount of glass for each ES Structure was set to 0. For each ES Structure type, the Net Explosive Weight (NEW) was varied between 3,629 $\mathrm{kg}$ and 453,592 $\mathrm{kg}$ and the range at which the probability of fatality became 1 was determined. This range and its corresponding charge weight were converted into a scaled distance.

These data were curve fit using generalized equations (1) of the form:

$$
X_{1 . i^{j}}=e^{\alpha_{1 i}+\beta_{1 i} \ln \left(N E W_{j}\right)+\gamma_{1 i}\left[\ln \left(N E W_{j}\right)\right]^{2}}, i=1,16 ; j=1,5
$$

The results of these curves fitting effort are given in Table 1, as the follow as:

Table 1 - $X_{1}$ Curve Fit- SI Units $\left(X_{1}\right.$ in $\mathrm{m} / \mathrm{kg} 1 / 3$ and NEW in $\mathrm{kg}$ )

\begin{tabular}{|c|c|c|c|c|}
\hline $\begin{array}{l}\text { Index } \\
i=1,16\end{array}$ & $\begin{array}{c}\text { Building } \\
\text { Type }_{i}\end{array}$ & $\alpha_{1 \mathrm{i}}$ & $\beta_{1 i}$ & $\gamma_{1 i}$ \\
\hline 1. & Small RC & -2.17004 & 0.38162 & -0.01175 \\
\hline 2. & Medium RC & -3.42340 & 0.52618 & -0.01536 \\
\hline 3. & Large RC (Tilt-up) & -6.92907 & 1.03103 & -0.03331 \\
\hline 4. & Small RMasonry & -2.29668 & 0.39858 & -0.01232 \\
\hline 5. & Medium RMasonry & -3.67141 & 0.58002 & -0.01813 \\
\hline 6. & Small U Brick & -2.29668 & 0.39858 & -0.01232 \\
\hline 7. & Medium UMasonry & -3.67141 & 0.58002 & -0.01813 \\
\hline 8. & Large RMasonry & -6.95185 & 1.03281 & -0.03332 \\
\hline 9. & Small PEMB & -2.29668 & 0.39858 & -0.01232 \\
\hline 10. & Medium PEMB & -3.43987 & 0.52820 & -0.01542 \\
\hline 11. & Large PEMB & -8.04584 & 1.17540 & -0.03763 \\
\hline 12. & Small Wood Frame & -2.29668 & 0.39858 & -0.01232 \\
\hline 13. & Medium Wood Frame & -3.43987 & 0.52820 & -0.01542 \\
\hline 14. & Medium Steel Stud & -3.43987 & 0.52820 & -0.01542 \\
\hline
\end{tabular}




\begin{tabular}{|l|l|l|l|l|}
\hline 15. & Modular Bldg./Trailer & -1.32048 & 0.26648 & -0.00787 \\
\hline 16. & Vehicle & -1.08143 & 0.23518 & -0.00684 \\
\hline
\end{tabular}

Taking into account the values corresponding to the 16 positions from Table 1, Equation (1) becomes:

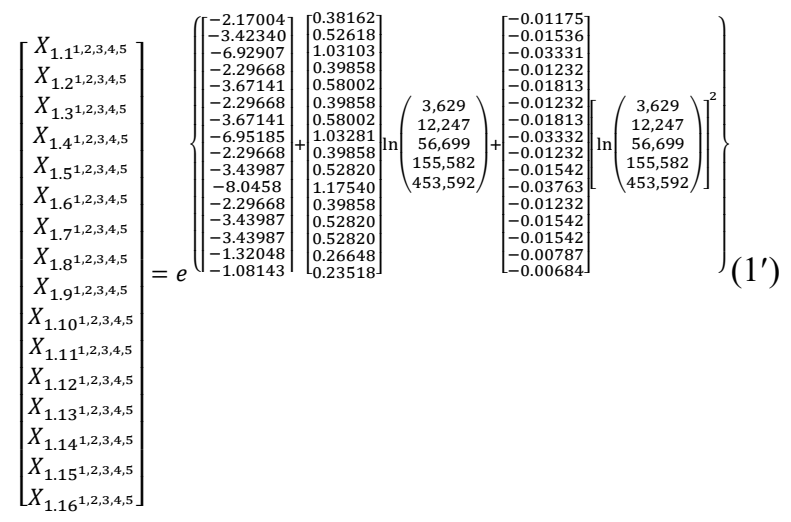

Example: The particular solution for $\mathrm{NEW}_{1}=3,629 \mathrm{~kg}$ is shown in relationship $\left(1^{\prime *}\right)$ :

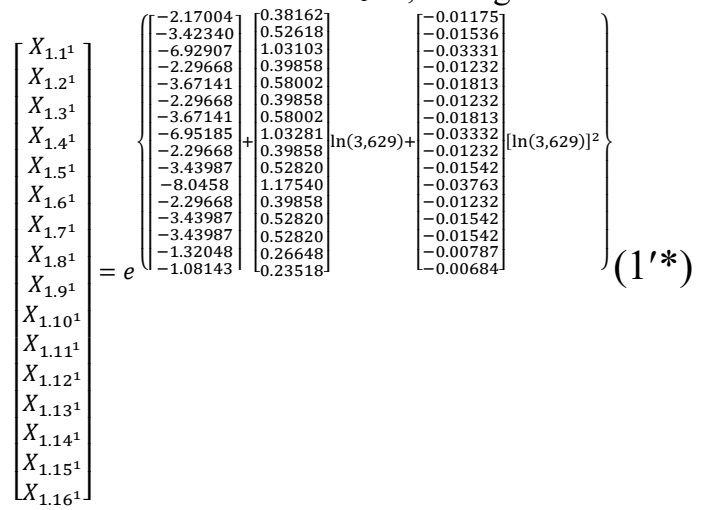

After performing the calculations for the $5(j=1,5)$ net quantities of explosive $\mathrm{NEW}_{\mathrm{j}}$, we obtain $\left(1^{\prime \prime}\right)$ :

\begin{tabular}{|c|c|c|c|c|c|c|c|c|c|c|}
\hline$X_{1.1^{1}}$ & [3.00 & {$\left[X_{1.1^{2}}\right]$} & [3.67 & {$\left[X_{1.1^{3}}\right]$} & {$[4.60]$} & {$\left[X_{1.1^{4}}\right.$} & [5.07 & {$\left[X_{1.1^{5}}\right]$} & {$[5.75]$} & \\
\hline$X_{1.2^{1}}$ & 2.10 & $X_{1.2^{2}}$ & 3.17 & $X_{1.2^{3}}$ & 4.20 & $X_{1.2^{4}}$ & 4.86 & $X_{1.2^{5}}$ & 5.57 & \\
\hline$X_{1.3^{1}}$ & 1.10 & $X_{1.3^{2}}$ & 2.50 & $X_{1.3^{3}}$ & 3.80 & $X_{1.3^{4}}$ & 4.57 & $X_{1.3^{5}}$ & 5.37 & \\
\hline$X_{1.4^{1}}$ & 2.90 & $X_{1.4^{2}}$ & 3.67 & $X_{1.4^{3}}$ & 4.50 & $X_{1.4^{4}}$ & 5.07 & $X_{1.4^{5}}$ & 5.72 & \\
\hline$X_{1.5^{1}}$ & 2.15 & $X_{1.5^{2}}$ & 3.13 & $X_{1.5^{3}}$ & 4.22 & $X_{1.5^{4}}$ & 4.89 & $X_{1.5^{5}}$ & 5.55 & \\
\hline$X_{1.6^{1}}$ & 2.90 & $X_{1.6^{2}}$ & 3.67 & $X_{1.6^{3}}$ & 4.50 & $X_{1.6^{4}}$ & 5.07 & $X_{1.6^{5}}$ & 5.72 & \\
\hline$X_{1.7^{1}}$ & 2.15 & $X_{1.7^{2}}$ & 3.13 & $X_{1.7^{3}}$ & 4.22 & $X_{1.7^{4}}$ & 4.89 & $X_{1.7^{5}}$ & 5.55 & \\
\hline$X_{1.8^{1}}$ & $=1.10$ & $X_{1.8^{2}}$ & $=2.43$ & $X_{1.8^{3}}$ & $=3.80$ & $X_{1.8^{4}}$ & 4.59 & $X_{1.8^{5}}$ & 5.34 & (1 \\
\hline$X_{1.9^{1}}$ & 2.90 & $X_{1.9^{2}}$ & -3.67 & $X_{1.9^{3}}$ & 4.52 & $X_{1.9^{4}}$ & 5.10 & $X_{1.9^{5}}$ & 5.72 & \\
\hline$X_{1.10^{1}}$ & 2.10 & $X_{1.10^{2}}$ & 3.13 & $X_{1.10^{3}}$ & 4.20 & $X_{1.10^{4}}$ & 4.87 & $X_{1.10^{5}}$ & 5.56 & \\
\hline$X_{1.11^{1}}$ & 0.85 & $X_{1.11^{2}}$ & 2.27 & $X_{1.11^{3}}$ & 3.70 & $X_{1.11^{4}}$ & 4.50 & $X_{1.11^{5}}$ & 5.30 & \\
\hline$X_{1.12^{1}}$ & 2.90 & $X_{1.12^{2}}$ & 3.67 & $X_{1.12^{3}}$ & 4.50 & $X_{1.12^{4}}$ & 5.07 & $X_{1.12^{5}}$ & 5.72 & \\
\hline$X_{1.13^{1}}$ & 2.10 & $X_{1.13^{2}}$ & 3.13 & $X_{1.13^{3}}$ & 4.20 & $X_{1.13^{4}}$ & 4.87 & $X_{1.13^{5}}$ & 5.56 & \\
\hline$X_{1.14^{1}}$ & 2.10 & $X_{1.14^{2}}$ & 3.13 & $X_{1.14^{3}}$ & 4.20 & $X_{1.14^{4}}$ & 4.87 & $X_{1.14^{5}}$ & 5.56 & \\
\hline & 3.55 & $X_{1.15^{2}}$ & 4.10 & $X_{1.15^{3}}$ & 4.78 & $X_{1.15^{4}}$ & 5.29 & $X_{1.15^{5}}$ & 5.80 & \\
\hline & โ3.75 & $X_{1.16^{2}}$ & โ4.23] & {$\left[\begin{array}{l}X_{1.16^{3}} \\
\end{array}\right.$} & $-4.86^{\rfloor}$ & $X_{1.16^{4}}$ & {$[5.34$} & {$\left[\begin{array}{l}1.15 \\
X_{1.16^{5}}\end{array}\right]$} & $-5.87]$ & \\
\hline
\end{tabular}

The curve fits given in these two tables are monotonically increasing and do not define a maximum range for $\mathrm{X}_{1}$. That has to be set separately. The maximum value for each $\mathrm{ES}$ Structure type was based on expert opinion of the scaled range at which the probably of 
fatality and injury would be 1.0. Once this maximum value was selected, the NEW corresponding to this value was determined for each ES Structure type. These results are shown in Table 2.

Table 2. - $\mathrm{X}_{1 \text { Maximum }}$ and $\mathrm{W}_{\mathrm{X} 1 \text { Maximum Values }}$

\begin{tabular}{|l|c|c|}
\hline $\begin{array}{c}\text { Building Type } \\
\text { (i=1.16) }\end{array}$ & $\begin{array}{c}\mathbf{X}_{\mathbf{1} \text { maxi }} \\
\left(\mathbf{m} / \mathbf{k g}^{\mathbf{1} / \mathbf{3}}\right)\end{array}$ & $\begin{array}{c}\mathbf{W}_{\mathbf{X} \text { maxi }} \\
(\mathbf{k g})\end{array}$ \\
\hline Small RC & 1.59 & 20,621 \\
\hline Medium RC & 1.59 & 47,566 \\
\hline Large RC (Tilt-up) & 1.59 & 78,905 \\
\hline Small RMasonry & 1.59 & 22,660 \\
\hline Medium RMasonry & 1.59 & 44,908 \\
\hline Small U Brick & 1.59 & 22,660 \\
\hline Medium UMasonry & 1.59 & 44,908 \\
\hline Large U Masonry & 1.59 & 80,226 \\
\hline Small PEMB & 1.59 & 22,660 \\
\hline Medium PEMB & 1.59 & 47,987 \\
\hline Large PEMB & 1.59 & 89,017 \\
\hline Small Wood Frame & 1.59 & 22,660 \\
\hline Medium Wood Frame & 1.59 & 47,987 \\
\hline Medium Steel Stud & 1.59 & 47,987 \\
\hline Modular Bldg./Trailer & 1.59 & 9,598 \\
\hline Vehicle & 1.59 & 6,804 \\
\hline
\end{tabular}

The selection process for $\mathrm{X}_{1}$ works as follows: Step 1: Select ES Structure type; Step 2: If the $\mathrm{NEW}>\mathrm{WX}_{1 \max }$, use the curve fit value for $\mathrm{X}_{1}$; Step 3: If the $\mathrm{NEW}<\mathrm{WX} 1$ max, use $\mathrm{X}_{1 \max }$

\section{b) Determining the $X_{2}, Y_{2}$ for each ES building type}

$\mathrm{X}_{2}$ is nominally defined as the scaled range and NEW at which $100 \%$ building damage occurs for each Structure type of ES. The following process was used to determine a value for $\mathrm{X}_{2}$. The data were curve fit using generalized equations (2) of the form:

$$
X_{2 . i^{j}}=e^{\alpha_{2 i}+\beta_{2 i} \ln \left(N E W_{j}\right)+\gamma_{2 i}\left[\ln \left(N E W_{j}\right)\right]^{2}+\delta_{2 i}\left[\ln \left(N E W_{j}\right)\right]^{3}}, i=1,16 ; j=1,5
$$

The results of this curve fitting effort are given in Table 3.

Table 3. - $\mathrm{X}_{2}$ Curve Fit - SI Units $\left(\mathrm{X}_{2}\right.$ in $\mathrm{m} / \mathrm{kg}^{1 / 3}$ and NEW in $\left.\mathrm{kg}\right)$

\begin{tabular}{|l|c|c|c|c|c|}
\hline $\begin{array}{c}\text { Index } \\
\mathbf{i}=\mathbf{1 , 1 6}\end{array}$ & \multicolumn{1}{|c|}{$\begin{array}{c}\text { Building } \\
\mathbf{T y p e}_{\mathbf{i}}\end{array}$} & $\boldsymbol{\alpha}_{\mathbf{2} \mathbf{i}}$ & $\boldsymbol{\beta}_{\mathbf{2} \mathbf{i}}$ & $\boldsymbol{\gamma}_{\mathbf{2} \mathbf{i}}$ & $\boldsymbol{\delta}_{\mathbf{2} \mathbf{i}}$ \\
\hline 1. & Small RC & -12.73845 & 2.50899 & -0.15063 & 0.00301 \\
\hline
\end{tabular}




\begin{tabular}{|l|l|c|c|c|c|}
\hline 2. & Medium RC & -14.17027 & 2.77310 & -0.16698 & 0.00335 \\
\hline 3. & Large RC (Tilt-up) & -7.10249 & 1.57460 & -0.09122 & 0.00174 \\
\hline 4. & Small RMasonry & -10.70652 & 2.22864 & -0.13727 & 0.00284 \\
\hline 5. & Medium RMasonry & -8.68339 & 1.87667 & -0.11472 & 0.00237 \\
\hline 6. & Small U Brick & -1.27841 & 0.73947 & -0.05725 & 0.00149 \\
\hline 7. & Medium UMasonry & -4.75780 & 1.37004 & -0.09843 & 0.00237 \\
\hline 8. & Large RMasonry & -4.22306 & 1.14189 & -0.07238 & 0.00154 \\
\hline 9. & Small PEMB & -4.10151 & 1.18355 & -0.07986 & 0.00180 \\
\hline 10. & MediumPEMB & -4.35187 & 1.17248 & -0.07565 & 0.00166 \\
\hline 11. & Large PEMB & -6.04594 & 1.30393 & -0.07101 & 0.00128 \\
\hline 12. & Small Wood Frame & -2.82161 & 0.95454 & -0.06669 & 0.00156 \\
\hline 13. & Medium Wood Frame & -6.00957 & 1.52721 & -0.10167 & 0.00226 \\
\hline 14. & Medium SteelStud & -7.55047 & 1.76845 & -0.11459 & 0.00249 \\
\hline 15. & Modular Bldg./Trailer & -2.02371 & 0.93024 & -0.07422 & 0.00198 \\
\hline 16. & Vehicle & -8.22443 & 1.83780 & -0.11731 & 0.00252 \\
\hline
\end{tabular}

Taking into account the values corresponding to the 16 positions in Table 4, Equation 2 becomes 2':

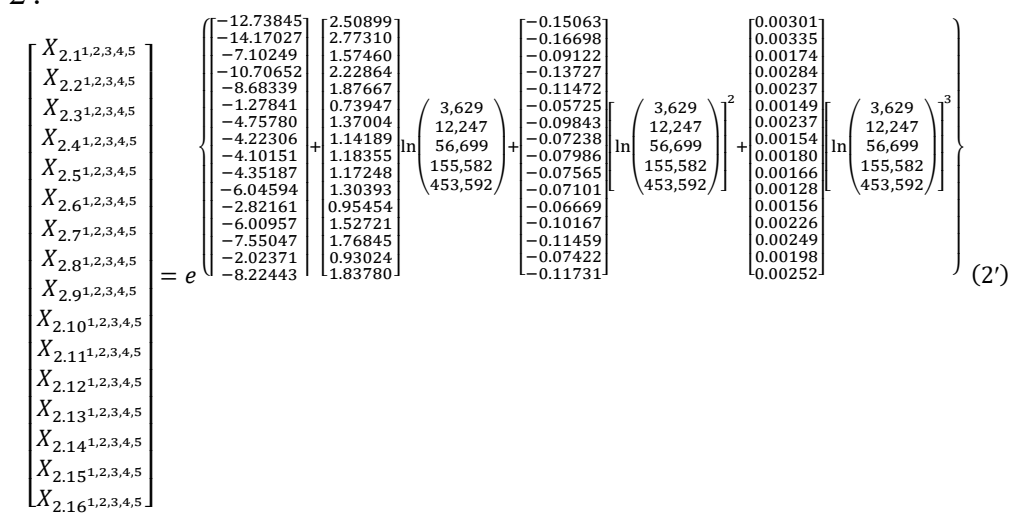

Example: The particular solution for $\mathrm{NEW}_{1}=3,629 \mathrm{~kg}$ is shown in relationship $\left(2^{\prime *}\right)$ :

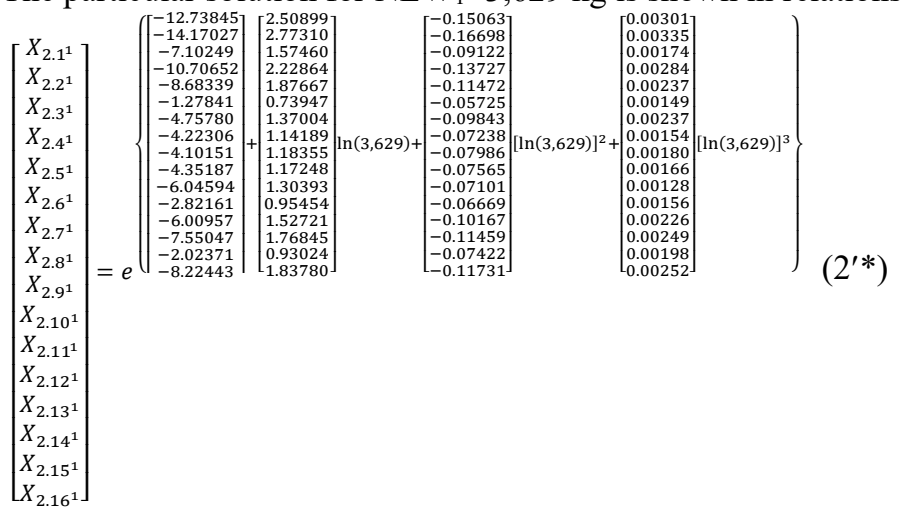

After performing the calculations for the $5(j=1,5)$ net quantities of explosive $\mathrm{NEW}_{\mathrm{j}}$, we 
obtain (2"):

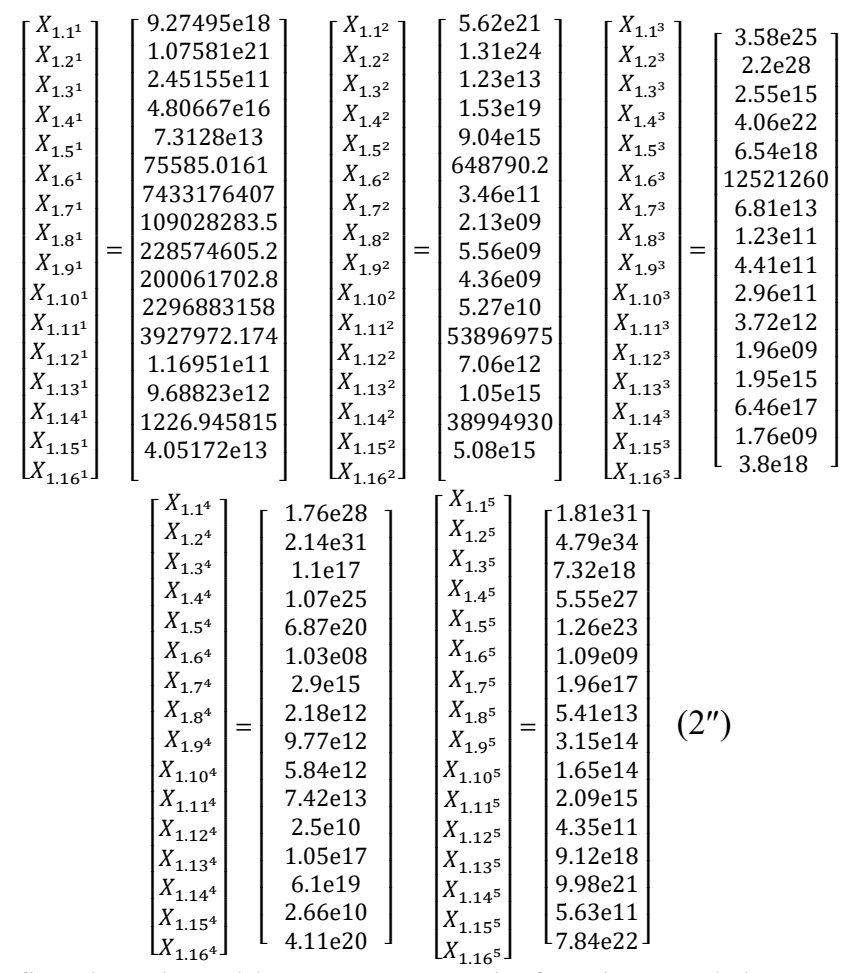

The curve fits given in Table 4 are monotonic functions and do not define a minimum range for $\mathrm{X}_{2}$. That has to be set separately. An additional constraint is that $\mathrm{X}_{1}$ must always be less than $\mathrm{X}_{2}$. The minimum value for each ES Structure type was based on expert opinion of the scaled range at which the standard logic model for fatality and injury would apply. Once this minimum value was selected, the NEW corresponding to this value was determined for each ES Structure type. These results for $X_{2}$ in $\mathrm{m} / \mathrm{kg}^{1 / 3}$ and NEW in $\mathrm{kg}$ are shown in Table 4.

Table 4. - $\mathrm{X}_{2}$ Minimum and $\mathrm{W}_{\mathrm{X} 2}$ MinimumValues

\begin{tabular}{|c|c|c|}
\hline $\begin{array}{c}\text { ES } \\
\text { Building Type }\end{array}$ & $\begin{array}{c}\mathbf{X}_{\mathbf{2} \text { min }} \\
(\mathbf{m} / \mathbf{k g}\end{array}$ & $\begin{array}{c}\mathbf{W}_{\mathbf{X} \mathbf{m} \text { min }} \\
(\mathbf{k g})\end{array}$ \\
\hline Small RC & 1.98 & 69,856 \\
\hline Medium RC & 1.98 & 82,954 \\
\hline Large RC (Tilt-up) & 1.98 & 4,069 \\
\hline Small R Masonry & 1.98 & 21,504 \\
\hline Medium R Masonry & 1.98 & 9,104 \\
\hline Small U Brick & 1.98 & 34 \\
\hline Medium U Masonry & 1.98 & 751 \\
\hline Large U Masonry & 1.98 & 914 \\
\hline Small PEMB & 1.98 & 620 \\
\hline Medium PEMB & 1.98 & 1,003 \\
\hline Large PEMB & 1.98 & 4,839 \\
\hline
\end{tabular}




\begin{tabular}{|c|c|c|}
\hline Small Wood Frame & 1.98 & 255 \\
\hline Medium Wood Frame & 1.98 & 1,833 \\
\hline Medium Steel Stud & 1.98 & 4,356 \\
\hline Modular Bldg/Trailer & 1.98 & 61 \\
\hline Vehicle & 1.98 & 9,055 \\
\hline
\end{tabular}

The selection process for $\mathrm{X}_{2}$ works as follows: Step 1: Select ES Structure type; Step 2: If the $\mathrm{NEW} \geq \mathrm{W}_{\mathrm{X} 2 \min }$ use the curve fit value for $\mathrm{X}_{2}$; Step 3: If the $\mathrm{NEW}<\mathrm{W}_{\mathrm{X} 2 \text { min }}$ use $\mathrm{X}_{2 \min }$

The parameters $\mathrm{X}_{2}, \mathrm{Y}_{2}$ has the values given in Table 5 .

Table 5. - $\mathrm{Y}_{2}$ (Probability of Fatality) Value at $\mathrm{X}_{2}$

\begin{tabular}{|l|c|}
\hline \multicolumn{1}{|c|}{ Building Type } & $\begin{array}{c}\text { Probability of Fatality } \\
\text { (100\% Building Damage) }\end{array}$ \\
\hline Small RC & 0.31800 \\
\hline Medium RC & 0.23590 \\
\hline Large RC (Tilt-up) & 0.27700 \\
\hline Small R Masonry & 0.18900 \\
\hline Medium R Masonry & 0.21750 \\
\hline Small U Brick & 0.17815 \\
\hline Medium U Masonry & 0.17815 \\
\hline Large R Masonry & 0.19380 \\
\hline Small PEMB & 0.12935 \\
\hline Medium PEMB & 0.14872 \\
\hline Large PEMB & 0.18365 \\
\hline Small Wood Frame & 0.11785 \\
\hline Medium Wood Frame & 0.14600 \\
\hline Medium Steel Stud & 0.16490 \\
\hline Modular Bldg/Trailer & 0.13095 \\
\hline Vehicle & 0.11170 \\
\hline
\end{tabular}

The region (transition region) between $\left(\mathrm{X}_{1}, \mathrm{Y}_{1}\right)$ and $\left(\mathrm{X}_{2}, \mathrm{Y}_{2}\right)$ will be spanned by a linear function. For any point $\mathrm{X}$, where $\mathrm{X}_{1}<\mathrm{X}<\mathrm{X}_{2}$, the corresponding value of $\mathrm{Y}$ will be computed by using the following relationship (3):

$$
Y=\left[\frac{\left(Y_{2}-1\right)}{\left(X_{2}-X_{1}\right)}\right] X+\left\{1-\left[\frac{\left(Y_{2}-1\right)}{\left(X_{2}-X_{1}\right)}\right] X_{1}\right\}(3)
$$

The fact $\mathrm{X}_{2}$ is set to a minimum a value (depending on the NEW) will introduce a small error (estimated to be a less than 10\%) in the calculated value of the $\mathrm{Y}$.

Example: For the "Small RC", building type, using the value data in Tables 3 and 5 for scaled distances $\mathrm{X}_{1 \max }=1.59$ and $\mathrm{X}_{2 \min }=1.98$, and respecting the conditions $\left(\mathrm{NEW}<\mathrm{W}_{\mathrm{X} 1 \max }=20,621\right.$ $\mathrm{kg}$ and $\mathrm{NEW}<\mathrm{W}_{\mathrm{X} 2 \mathrm{~min}}=69,856 \mathrm{~kg}$ ), the equation for the transition region becomes $\left(3^{\prime}\right)$ :

$$
Y=\left[\frac{(0.318-1)}{(1.98-1.59)}\right] X+\left\{1-\left[\frac{(0.318-1)}{(1.98-1.59)}\right] \cdot 1.59\right\}\left(3^{\prime}\right)
$$


After performing the calculations we obtain the equation (3"):

$$
Y=-1.7488 X+3.7806\left(3^{\prime \prime}\right)
$$

\section{Results and discussion}

The results which can obtained by use the values of the Table 2 and Table 4 are shown in Figure 3:

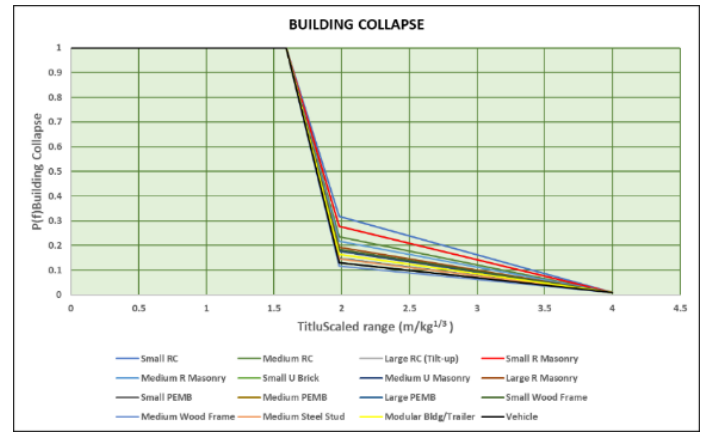

Fig. 3. Building Collapse Diagram

Using the truncated normal distribution curves shown in Figure 4, the probability of fatality as a function of structural damage, $\operatorname{Pf}(\mathrm{bc})$, is determined.

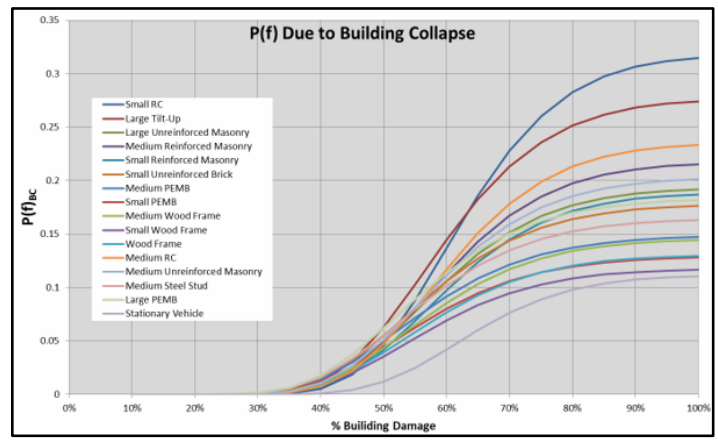

Fig. 4. Building Collapse Curves

It should be noted that the maximum probability of fatality for building collapse is less than $40 \%$, even for $100 \%$ predicted building damage $[8,9,10]$. The building damage refers to the usability of the structure and does not imply that the structure has completely collapsed. A structure can experience $100 \%$ building damage, requiring replacement, and still have sufficient structural integrity to allow for evacuation of personnel. Even when a structure has experienced severe damage to the point of requiring total replacement, the probability of fatality is not $100 \%$. The probability of fatality for building collapse, $\mathrm{P}_{\mathrm{f}(\mathrm{bc})}$, term can reach 1.0 when the ES structure is relatively close to the explosion. However, determining the probability of fatality close-in relies on the Simplified Close-In Fatality Mechanism Model (Figure 1). The scaled ranges $\left(\mathrm{X}_{1}\right.$ and $\left.\mathrm{X}_{2}\right)$ that govern when Simplified Close-In Fatality Mechanism Model criteria apply are based on the ES structure typ 


\section{Conclusions}

The paper highlights how to customize the generalized model of the mechanism for producing event scenarios for the structural collapse of a building affected by the explosion.

The process of quantitative risk assessment associated with explosion phenomena as a result of the detonation of an explosive charge, allows estimating result indicators based on the use of algorithms and models specific to associated hazards, in order to model the effects and consequences of event scenarios. In this sense, the simplified approach of the mechanism of producing the state of fatality/structural collapse is identified with the solution of the generalized model of consequences for this type of scenario, which from a conceptual point of view is defined by an event characteristic represented in a rectangular system, in the XOY plane, in which on the ordinate is the parameter Pf/e which represents the probability of fatality/structural collapse and on the abscissa is found the scaled distance expressed in $(\mathrm{m} / \mathrm{kg} 1 / 3)$.

This event characteristic defines 3 main regions of operationalization of the conceptual model, respectively: the stable region in the form of a plateau (constant evolution), the transition region (decreasing variable evolution) and the standard-logical region (characterized by a certain degree of confidence in the results scientific aspects of the algorithm).

\section{References}

1. M. Hardwick, J. Hall, J. Tatom, Baker R., Approved Methods and Algorithms for DoD Risk-Based Explosive Siting, DDESB Technical, p.14-21, July 2019.

2. A. Arnauld, P. Nicole, Logic or the Art of Thinking, 1996.

3. T. Ross, J. Tatom, M. Swisdak, M. Ortel, S. Van Horn, B. Whitworth, D. Nichols, Safety Assessment for Risk, A-P-T- RESEARCH, INC, Huntsville, USA, June 2015.

4. T. Pfitzer, Use of Fatality as the Measure of Risk, Tech Memo E1-00300, A-P-T Research, Inc., Huntsville, AL., May 2002.

5. Institute of Makers of Explosives Safety Analysis for Risk - User's Reference Manual, Version 2, October, 2014.

6. AISC Design Guide 26, Design of Blast Resistant Structures, (American Institute of Steel Construction, 2013)

7. DoD, UFC 4-023-03: Design of buildings to resist progressive collapse. (US Department of Defense, Washington, DC, USA, 2009)

8. J., D., Chrostowski, P.,D., Wilde, G. Wenshui, Blast Damage, Serious Injury and Fatality Models for Structures and Windows, ACTA Torrance CA, July 2001.

9. BIPS 05, Preventing Structures from Collapsing to Limit Damage to Adjacent Structures and Additional Loss of Life when Explosives Devices Impact Highly Populated Urban Centers, (Homeland Security, 2011)

10. ASCE/SEI 59-11, Blast Protection of Buildings, 2011 